\title{
Non-myeloid cells are major contributors to innate immune responses via production of monocyte chemoattractant protein-1/CCL2
}

\section{Teizo Yoshimura ${ }^{1}$, Carole Galligan ${ }^{1}$, Munehisa Takahashi ${ }^{1}$, Keqiang Chen ${ }^{1}$, Mingyong Liu ${ }^{1}$, Lino Tessarollo ${ }^{2}$ and Ji Ming Wang ${ }^{1}$}

' Laboratory of Molecular Immunoregulation, Cancer and Inflammation Program, Center for Cancer Research, National Cancer Institute, Frederick, MD, USA

${ }^{2}$ Mouse Cancer Genetics Program, Center for Cancer Research, National Cancer Institute, Frederick, MD, USA

Edited by:

Klaus Ley, La Jolla Institute for Allergy and Immunology, USA

Reviewed by:

Santos Mañes, Consejo Superior Investigaciones Científicas, Spain Yuqing Huo, Georgia Reagents

University, USA

\section{*Correspondence:}

Teizo Yoshimura, Laboratory of Molecular Immunoregulation, Cancer and Inflammation Program, Center for Cancer Research, National Cancer Institute, Building 559, Room 2, P.O Box B, Frederick, MD 21702-1201, USA

e-mail: yoshimut@mail.nih.gov
Monocyte chemoattractant protein-1 (MCP-1)/CCL2 is a chemokine regulating the recruitment of monocytes into sites of inflammation and cancer. MCP-1 can be produced by a variety of cell types, such as macrophages, neutrophils, fibroblasts, endothelial cells, and epithelial cells. Notably, macrophages produce high levels of MCP-1 in response to proinflammatory stimuli in vitro, leading to the hypothesis that macrophages are the major source of MCP-1 during inflammatory responses in vivo. In stark contrast to the hypothesis, however, there was no significant reduction in MCP-1 protein or the number of infiltrating macrophages in the peritoneal inflammatory exudates of myeloid cell-specific MCP-1-deficient mice in response to i.p injection of thioglycollate or zymosan A. Furthermore, injection of LPS into skin air pouch also had no effect on local MCP-1 production in myeloid-specific MCP-1-deficient mice. Finally, myeloid-specific MCP-1-deficiency did not reduce MCP-1 mRNA expression or macrophage infiltration in LPS-induced lung injury. These results indicate that non-myeloid cells, in response to a variety of stimulants, play a previously unappreciated role in innate immune responses as the primary source of MCP-1.

Keywords: chemokines, inflammation, innate immunity, myeloid cells, gene knockout mice

\section{INTRODUCTION}

Chemokines play a pivotal role in guiding leukocyte trafficking during inflammatory responses (1). Although this is considered their primary function, chemokines also control the organization of the entire hematopoietic/lymphopoietic system, including the regulation of stem cell maturation, the formation of secondary lymphoid tissues, and angiogenesis (2-5). Moreover, chemokines and their receptors are intimately involved in the orchestration of inflammatory responses, in the pathogenesis of acquired immunodeficiency syndrome (6) and the progression of cancer (7). Therefore, they are considered to be important potential therapeutic targets in these diseases (8).

Some chemokines, such as stromal cell-derived factor $1 /$ CXCL12, are constitutively produced by restricted cell types, such as stromal cells; however, production of many chemokines is induced in multiple cell types upon tissue injury (9). Monocyte chemoattractant protein-1 (MCP-1) is a potent monocyte chemoattractant that also attracts $\mathrm{T}$ cells, NK cells, and dendritic cells (10). It is produced by a variety of cell types, including macrophages, endothelial cells (ECs), epithelial cells, and neutrophils, in response to proinflammatory stimuli (11). Macrophages have been demonstrated to produce MCP-1 at many human and animal disease sites; thus, they are considered to be an important cellular source of MCP-1 and contribute to the further recruitment of monocytes, $\mathrm{T}$ cells, and DCs during inflammatory responses $(12,13)$. However, it remains unclear whether, in a complex environment of injured tissue, other cell types also produce significant levels of MCP-1.
Determination of the exact cell types producing MCP-1 in diseases and the mechanisms by which they produce MCP-1 may allow us to target those cells for effective inhibition of its production.

To determine the precise cellular source of MCP-1 in immune responses, we generated MCP- $1^{\text {flox/flox }}$ mice for tissue-specific deletion of this chemokine. In the present study, we used myeloid cell-specific MCP-1-deficient mice to evaluate whether myeloid cells, such as neutrophils and macrophages, are the main source of MCP-1 in innate immune responses. Here we report that in contrast to the original hypothesis, myeloid cell-specific MCP1-deficiency did not reduce MCP-1 production in experimental mouse peritonitis, skin air pouch, or LPS-induced lung injury. Thus, non-myeloid cells are major MCP-1 producers and play a previously unappreciated role in the development of innate immune responses.

\section{MATERIALS AND METHODS MICE}

The generation of MCP- 1 foxed mice (MCP- $1^{\text {flox } /+}$ ) mice was previously described (14). MCP-1 $1^{\text {flox } /+}$ mice was backcrossed to WT C57BL/6Ncr mice (Charles River, Frederick, MD, USA) for 10 generations, and the resulting mice were then crossed to LysMCre mice (15) on a C57BL/6 background to generate LysMCre+, MCP-1 $1^{\text {flox/flox }}$ (JAX Stock No. 023347, B6;129$\mathrm{Ccl} 2<\mathrm{tm} 1$ Tyos $>/ \mathrm{J})$. All experimental protocols for this study were approved by the Frederick National Laboratory for Cancer Research Animal Care and Use Committee, Frederick, MD, USA. 


\section{INDUCTION OF TG- OR ZYMOSAN A-INDUCED PERITONITIS}

Eight- to twelve-week-old mice were intraperitoneally injected with $1 \mathrm{ml}$ of sterile, 3\% TG broth (Difco Laboratories, Detroit, MI, USA) or $0.5 \mathrm{ml}$ of $400 \mu \mathrm{g} / \mathrm{ml}$ zymosan A (Sigma-Aldrich, St. Louis, MO, USA). The mice were sacrificed $4 \mathrm{~h}$ after injection to measure MCP- 1 concentration or 4 days to evaluate macrophage infiltration. Peritoneal exudates were harvested by peritoneal lavage using $5 \mathrm{ml}$ cold PBS. The concentration of peritoneal exudates cells (PEC) was counted using a hemocytometer under microscope. Cells were applied to microscope slides, using a cytospin centrifuge (Shandon), and stained with Diff-Quick (Baxter Healthcare Corp.), and differential cell counts were obtained by morphological analysis. The number of macrophages was calculated, using the total cell number and the percentage of macrophages in the same sample.

\section{AIR POUCH MODEL}

Air pouches were raised on the dorsum of 6- to 8-week-old mice as described previously (16). Mice with a well-formed air pouch were randomized into groups. Each mouse was given an injection with $1 \mathrm{ml}$ endotoxin-free PBS alone or PBS containing $1 \mathrm{mg}$ LPS (Sigma-Aldrich) into the air pouches. Four hours after injection, mice were euthanized by $\mathrm{CO} 2$ asphyxiation, and cells in the air pouches were harvested with $2 \mathrm{ml}$ PBS with heparin.

\section{LPS-INDUCED LUNG INJURY}

Mice were placed in a Mass Dosing Chamber (PLY5000, Buxco Research Systems, Wilmington, NC, USA) connected to an Aerogen Aeroneb nebulizer in a ventilated biological hood. LPS (100 or $1000 \mu \mathrm{g} / \mathrm{ml}$ in $10 \mathrm{ml}$ PBS) was added to the nebulizer and aerosol was produced. Mice were exposed to LPS aerosol for $30 \mathrm{~min}$, and then returned to cages. Four or $24 \mathrm{~h}$ after LPS exposure, mice were euthanized by $\mathrm{CO} 2$ and bronchoalveolar lavage fluids (BALFs) were collected by injecting $1 \mathrm{ml}$ PBS into the lung through trachea.

\section{NORTHERN AND SOUTHERN BLOTTING}

Northern blot and southern analyses were performed as described $(14,17)$. Filters were hybridized at $42^{\circ} \mathrm{C}$ overnight in $50 \%$ formamide, $5 \times$ SSC, $5 \times$ Denhardt's solution, $50 \mu \mathrm{g} / \mathrm{ml}$ sheareddenatured salmon sperm DNA, $1 \%$ SDS, and $1 \times 10^{6} \mathrm{dpm} / \mathrm{ml}$ of ${ }^{32}$ P-labeled cDNA probe (Perkin Elmer, Cambridge, MA, USA). Filters were washed twice with $2 \times$ SSC, $0.5 \%$ SDS at room temperature for $15 \mathrm{~min}$ and $0.1 \times \mathrm{SSC}, 0.5 \% \mathrm{SDS}$ at $60^{\circ} \mathrm{C}$ for $30 \mathrm{~min}$ prior to autoradiographic exposure.

\section{ELISA}

The concentrations of MCP-1 were measured in the Lymphokine Testing Laboratory, Clinical Services Program, SAIC-Frederick, Frederick, MD, USA with an ELISA kit specific for mouse MCP-1 (R\&D Systems).

\section{STATISTICAL ANALYSIS}

Statistical analysis was performed by Student's $t$-test or Log-rank (Mantel-Cox) test, using the GraphPad Prism, Version 4 and 5, GraphPad Software, San Diego, CA, USA. A value of $p<0.05$ was considered to be statistically significant.

\section{RESULTS}

\section{GENERATION OF MYELOID CELL-SPECIFIC MCP-1-DEFICIENT MICE}

Myeloid cell-specific MCP-1-deficient mice were generated by crossing MCP-1 $1^{\text {flox/flox }}$ mice to LysMCre ${ }^{+} \mathrm{MCP}-1^{\text {flox/flox }}$ mice. We first examined the efficiency of MCP-1 gene deletion in myeloid cells. As shown in Figure 1A, there was an approximately $70 \%$ reduction in the amount of WT MCP-1 allele in TG-induced PEC of LysMCre ${ }^{+}, \mathrm{MCP}-1^{\text {flox/flox }}$ mice by Southern blotting, and approximately $90 \%$ reduction in MCP-1 concentration in the culture supernatants of TG-induced PEC from LysMCre ${ }^{+}$, MCP- $1^{\text {flox/flox }}$ mice activated by LPS for $24 \mathrm{~h}$ (Figure 1B). When myeloid cells, especially macrophages, were enriched by incubating $\mathrm{PEC}$ in a tissue culture plate at $37^{\circ} \mathrm{C}$ for $3 \mathrm{~h}$ and removing non-adherent cells, almost $100 \%$ of the MCP-1 allele was the mutated allele (Figure 1C). These results indicate that the MCP1 gene was effectively deleted in the myeloid cells of LysMCre ${ }^{+}$, MCP- $1^{\text {flox/flox }}$ mice.

\section{MYELOID-SPECIFIC MCP-1 DELETION DID NOT AFFECT SERUM MCP-1 CONCENTRATION IN ADULT MICE}

Previous reports have shown detectable levels of MCP-1 in the sera of healthy human or mice $(18,19)$. To determine whether

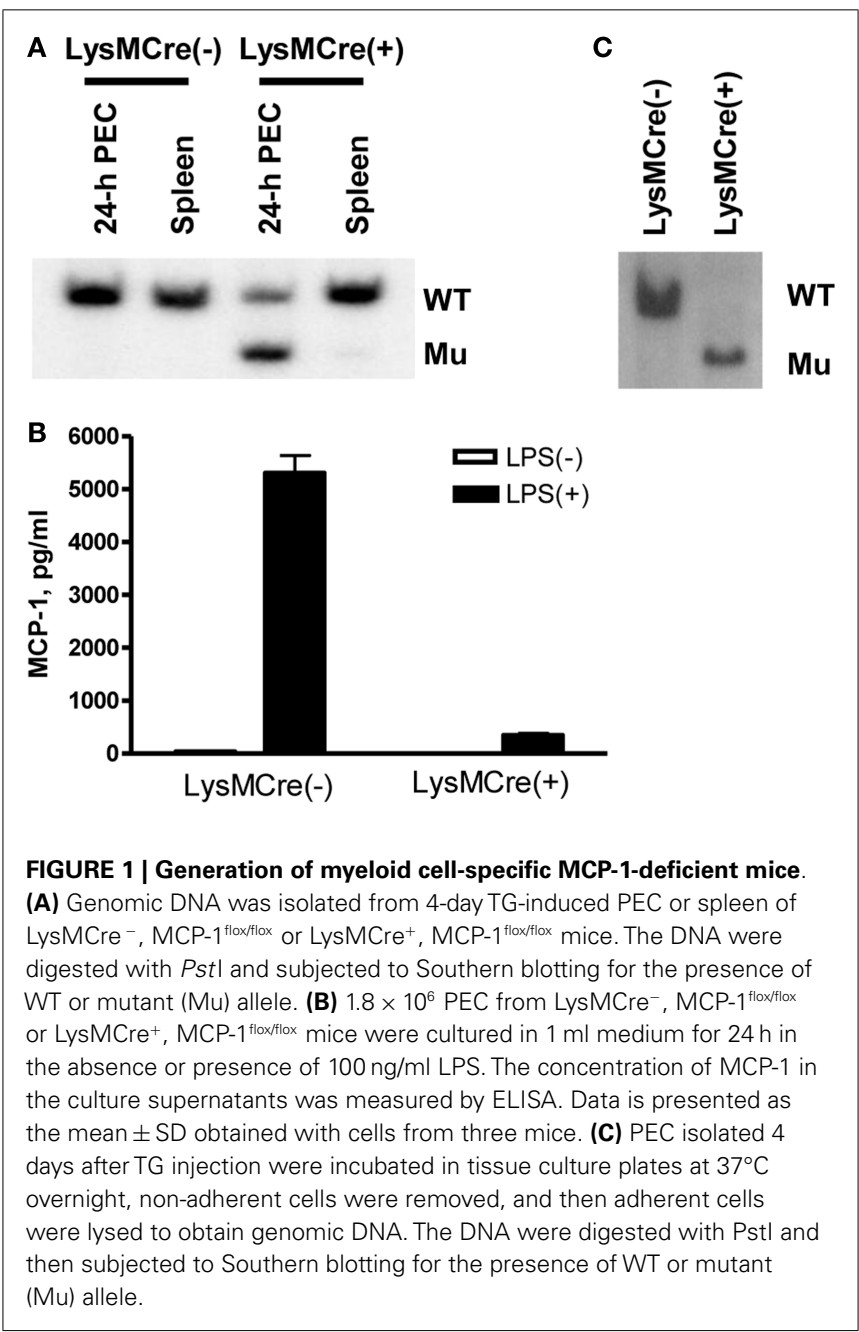


MCP-1-deficiency in myeloid cells affects the MCP-1 level in sera, we obtained sera from adult MCP-1 flox/flox or LysMCre ${ }^{+}, \mathrm{MCP}-$ $1^{\text {flox/flox }}$ mice and measured MCP-1 concentration. As shown in Figure 2, there was no difference in serum MCP-1 concentration between MCP-1 ${ }^{\text {flox/flox }}$ and LysMCre ${ }^{+}, \mathrm{MCP}^{\text {flox/flox }}$ mice, indicating that myeloid cells do not play a significant role in MCP-1 production under steady state conditions.

\section{MYELOID-SPECIFIC MCP-1 DELETION HAD NO EFFECT ON MCP-1 PRODUCTION OR MACROPHAGE INFILTRATION IN PERITONITIS}

To determine whether myeloid cells contribute to MCP-1 production during innate immune responses, we induced peritonitis in MCP-1 $1^{\text {flox/flox }}$ and LysMCre ${ }^{+}, \mathrm{MCP}-1^{\text {flox/flox }}$ mice by i.p injection of TG or zymosan A and examined the concentration of MCP-1 and the number of accumulated macrophages in peritoneal exudates. We previously demonstrated that i.p. injection of TG or zymosan A into normal mice induced the production of MCP-1 which peaked at $4 \mathrm{~h}$ and systemic MCP-1 deficiency significantly reduced the accumulation of macrophages into the peritoneal cavity (14). As shown in Figures 3A,B, similar levels of MCP-1 protein were detected in peritoneal exudates of both mouse strains after i.p. injection with either TG or zymosan A. Additionally, there was no difference in the number of macrophages that accumulated in the peritoneal cavity 4 days after induction of peritonitis (Figures 3C,D).

To further evaluate the role of peritoneal resident macrophages in MCP-1 production in TG-induced peritonitis, we adoptively transferred WT resident peritoneal cells into the peritoneal cavities of systemic MCP-1 $1^{-1-}$ mice, followed by TG-injection. As shown in Figure 3E, there was no detectable level of MCP1 in the peritoneal exudates of $\mathrm{MCP}-1^{-/-}$mice that received adoptively transferred WT peritoneal resident cells $4 \mathrm{~h}$ after TGinjection. These results indicate that myeloid cells are not a major source of MCP-1 during TG- or zymosan A-induced peritonitis.

\section{MYELOID-SPECIFIC MCP-1 DELETION DID NOT AFFECT MCP-1 PRODUCTION IN LPS-INDUCED INFLAMMATION IN SKIN AIR POUCH}

It was previously shown that MCP-1 is produced during arthritis in human and in animal models $(20,21)$. We used an air pouch model as a tool to evaluate the role of myeloid cells in MCP-1 production during arthritis. Since repeated injection of air into subcutaneous connective tissue in the skin results in the formation of a cavity (air pouch) with a lining structure closely resembling synovial tissue, the air pouch model has been used as a convenient model for studying the behavior of synovial lining tissues (22). We injected PBS or LPS (1 mg in $1 \mathrm{ml} \mathrm{PBS}$ ) into the air pouch and measured MCP-1 concentration in the lavage after $4 \mathrm{~h}$. As shown in Figure 4, only low levels of MCP1 were detected in the lavage after PBS injection, whereas high levels of MCP-1 were detected in the lavage after LPS injection in both MCP-1 $1^{\text {flox/flox }}$ and LysMCre ${ }^{+}, \mathrm{MCP}^{\text {flox/flox }}$ mice with no significant difference between the two strains. These results indicate that, similar to peritonitis, myeloid cells are not a major source of MCP-1 during LPS-induced inflammation in skin air pouch.

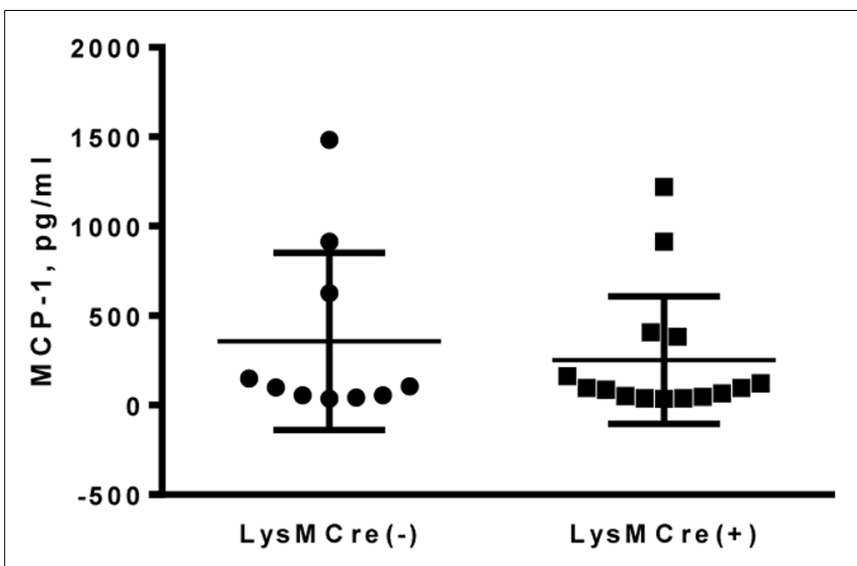

FIGURE 2 | MCP-1-deficiency in myeloid cells did not affect serum MCP-1 concentrations in normal adult mice. Serum was collected from 18- to 20-weeks untreated MCP-1 $1^{\text {floxfllox }}$ or LysMCre ${ }^{+}, \mathrm{MCP}-1^{\text {floxflox }}$ mice and MCP-1 concentration was measured by ELISA.

\section{MYELOID-SPECIFIC MCP-1 DELETION DID NOT AFFECT MCP-1 PRODUCTION OR MACROPHAGE INFILTRATION IN LPS-INDUCED LUNG INJURY}

We next examined LPS-induced lung injury in mice, a model similar to human lung injury that occurs during pneumonia or sepsis. A number of macrophages reside in both alveolar space and lung tissues and these macrophages can be activated in response to LPS to produce MCP-1. We obtained mouse lungs 6 and $24 \mathrm{~h}$ after the exposure to LPS and evaluated MCP-1 mRNA expression in whole lung tissue. As shown in Figure 5A, there was no detectable MCP-1 mRNA in normal lung tissue of either MCP- $1^{\text {flox/flox }}$ or LysMCre ${ }^{+}$, MCP- $1^{\text {flox/flox }}$ mice. After LPS treatment, the expression of MCP$1 \mathrm{mRNA}$ in the lung was readily detectable at $4 \mathrm{~h}$ and returned almost to the basal levels by $24 \mathrm{~h}$ in both strains. Thus, MCP-1 deletion in myeloid cells did not alter the level of MCP-1 mRNA in LPS-challenged lungs. Accordingly, there was no decrease in the number of macrophages contained in BALFs of LysMCre ${ }^{+}$, MCP- $1^{\text {flox/flox }}$ mice $24 \mathrm{~h}$ after LPS exposure (Figure 5B).

\section{DISCUSSION}

Macrophages play an important role in the initiation and development of innate immune responses by producing an array of proinflammatory mediators, including cytokines and chemokines (23). Since macrophages produce high levels of MCP-1 in culture in vitro and they were often associated with MCP-1 in inflamed tissues, we hypothesized that monocyte/macrophage-specific deletion of the MCP-1 gene might lead to decreased MCP-1 levels at inflammatory sites and subsequent reduction in macrophage accumulation. To test this hypothesis, we generated myeloid cellspecific MCP-1-deficient mice, and evaluated the role of myeloid cells, especially macrophages, in MCP-1 production during innate immune responses. In contrast to our hypothesis, deletion of the MCP-1 gene in myeloid cells had no effects on either MCP-1 production or subsequent macrophage infiltration in three models of innate immune response, indicating that non-myeloid cells are critical in regulating the development of innate immune responses as the primary MCP-1-producing cells. 


\section{A TG}

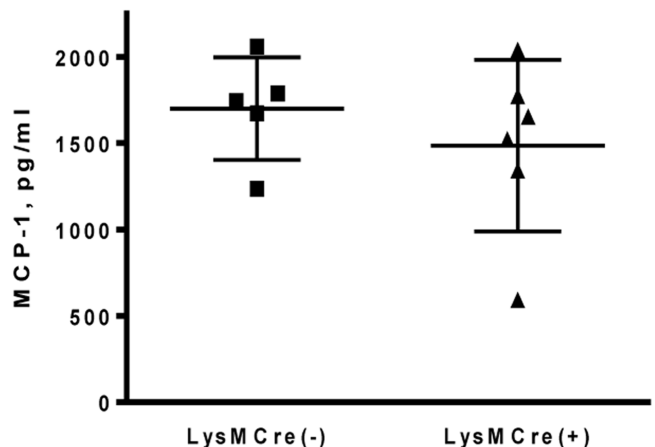

C TG

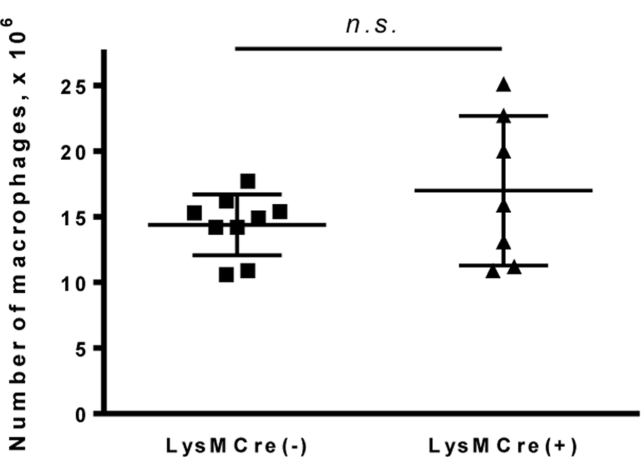

E

\section{Adoptive transfer, TG}

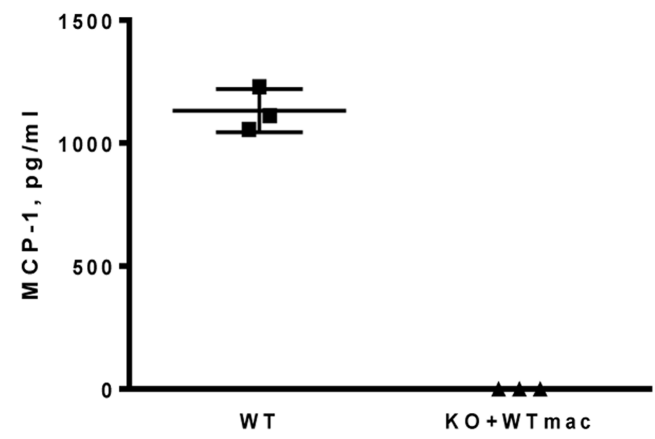

FIGURE 3 | MCP-1-deficiency in myeloid cells does not affect the concentration of MCP-1 or the accumulation of macrophages in peritoneal fluids in response to TG or zymosan $\mathbf{A}$. (A,B) Peritoneal fluids were collected $4 \mathrm{~h}$ after i.p. injection of $1 \mathrm{ml}$ of $3 \% \mathrm{TG}$ (A) or $0.5 \mathrm{ml}$ of $400 \mu \mathrm{g} / \mathrm{ml}$ zymosan A (B) and the concentration of MCP-1 in cell-free fluids was measured by ELISA. Data is presented as the mean \pm SD obtained from the indicated number of mice. (C,D) Mice were i.p. injected with $1 \mathrm{ml}$ of $3 \%$ TG (C) or $0.5 \mathrm{ml}$ of $400 \mu \mathrm{g} / \mathrm{ml}$ zymosan A (D). Peritoneal cavities were flushed

Sera from healthy human donors contain a wide range of MCP-1 concentrations (18), presumably due to variable degree of stimulation. Sera from normal mice also contain a detectable level of MCP-1 (19). In the present study, myeloid cell-specific
B Zymosan A

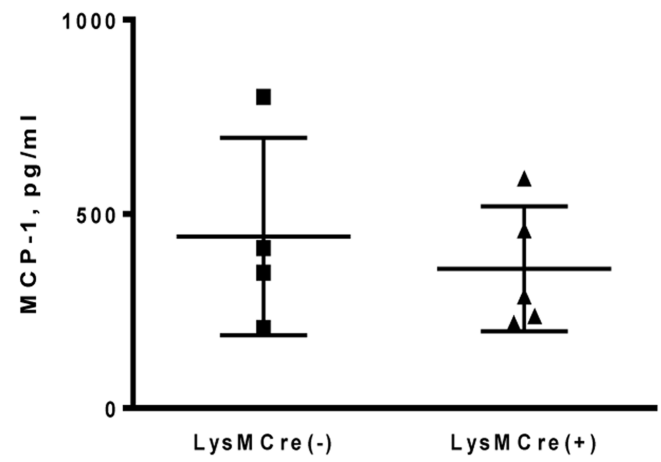

D Zymosan A

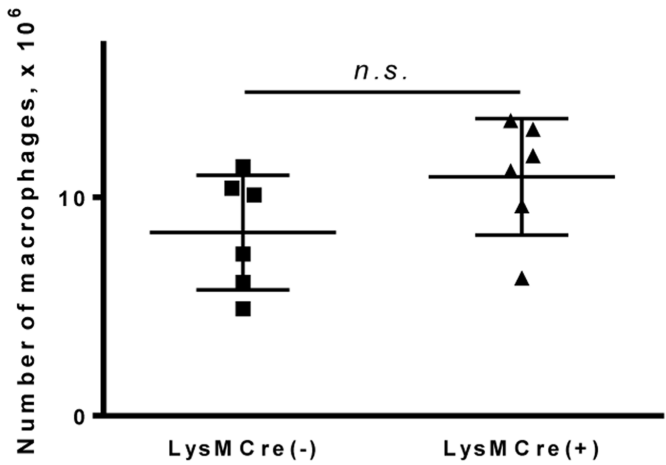

with $5 \mathrm{ml}$ PBS 4 days after injection and the number of macrophages was counted. Data is presented as the mean \pm SD. (E) Peritoneal resident cells were collected from WT C57BL/6 mice and transferred into the peritoneal cavity of MCP-1 KO mice. WT and MCP-1 KO mice adoptive transferred with WT peritoneal cells were i.p. injected with $1 \mathrm{ml}$ of $3 \%$ TG. Peritoneal cavities were flushed with $5 \mathrm{ml}$ PBS $4 \mathrm{~h}$ after injection and the concentration of MCP-1 in the peritoneal fluids was measured by ELISA. Data is presented as the mean $\pm S D$ obtained from three mice. 


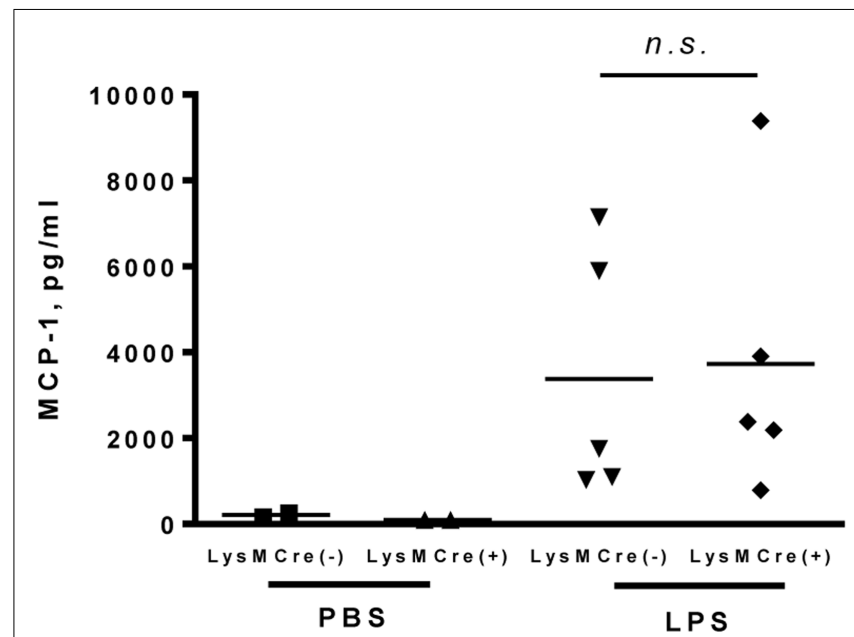

FIGURE 4 | MCP-1-deficiency in myeloid cells does not alter the production of MCP-1 in response to LPS in air pouches. Each mouse was given an injection with $1 \mathrm{ml}$ PBS or PBS containing $1 \mathrm{mg}$ LPS into the air pouch. Four hours after injection, air pouches were flushed with $2 \mathrm{ml}$ PBS with heparin. The concentration of MCP-1 in the air pouch fluids was measured by ELISA. Data is presented as the mean \pm SD.

by immunohistochemistry. Although foam cells infiltrating the aorta were strongly positive for MCP-1, ECs were also positive. Furthermore, aortic ECs from an individual with no apparent atherosclerosis were positive for MCP-1 (24). Thus, non-myeloid cells, likely ECs, appear to be the source of MCP-1 found in sera of human and mice.

To determine the cellular source of MCP-1 in innate immune responses, we utilized two mouse peritonitis models, induced by TG or zymosan A. The MCP-1 concentration in the exudates of myeloid cell-specific MCP-1-deficient mice was not decreased in either peritonitis model, indicating that non-myeloid cells are the primary source of MCP-1. The role of peritoneal resident macrophages and mast cells in chemokine production in acute inflammation was previously investigated in mouse peritonitis models (25). Depletion of either macrophages or mast cells had no effect on the production of MCP-1 or the neutrophil attracting chemokine KC after TG-injection into WT mice. Removal of either macrophages or mast cells resulted in attenuation of neutrophil infiltration into the peritoneal cavity of WT mice without affecting the levels of MCP-1 and KC in response to intraperitoneal administration of LPS; however, depletion of resident mast cells inhibited neutrophil accumulation as well as MCP-1 and KC production in response to zymosan, suggesting that mast cells may be the primary source of MCP-1 in peritonitis caused by certain stimuli, such as zymosan. Mesothelial cells form a monolayer that lines the pleural, peritoneal, and pericardial cavities as well as internal organs (26), and produce chemokines, including $\mathrm{KC}$ and MCP-1, in response to ligands of Nod1 or TLRs (27). Therefore, mesothelial cells may be a potential cellular source of MCP-1 in our study. These findings support our conclusion that nonmyeloid cells in the peritoneal cavity, but not resident peritoneal macrophages, are the major source of MCP-1 in innate immune responses.

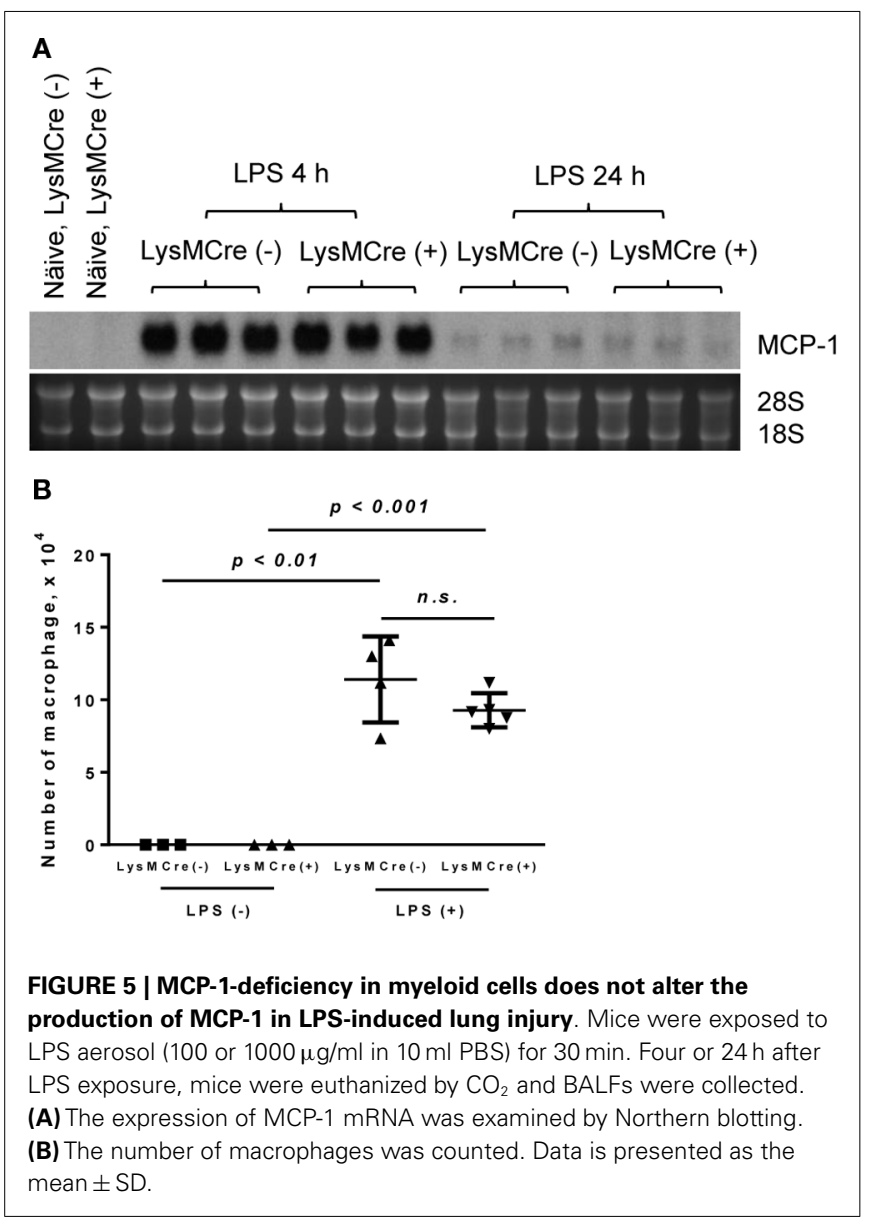

In addition to the peritonitis models, we used a LPS-induced lung injury model to identify the source of MCP-1 in innate immune responses. A previous study indicated that MCP-1 produced by alveolar macrophages mediated systemic inflammation caused by acute alveolar hypoxia, using rats in which alveolar macrophages were depleted by airway instillation of clodronatecontaining liposomes (28). In our study using genetically engineered mice, we demonstrate that non-myeloid cells were the primary source of MCP-1 in LPS-induced lung injury. Additionally, intraperitoneal injection of LPS in both MCP-1 $1^{\text {flox/flox }}$ and LysMCre ${ }^{+}, \mathrm{MCP}-1^{\text {flox/flox }}$ mice induced high levels of MCP-1 mRNA in the lung of both strains (data not shown). Thus, nonmyeloid cells in the lung, such as bronchoalveolar cells which have the capacity to express MCP-1 (29), likely are the cellular source of MCP-1 to regulate the accumulation of macrophages in this model.

Myeloid cells, such as macrophages, have been thought to be the major contributor to the development of innate immune responses by releasing a variety of proinflammatory mediators, including chemokines. However, our study has clearly demonstrated that non-myeloid cells play a previously unappreciated role in the development of innate immune response by acting as the major producer of MCP-1. While we did not observe an effect of myeloid-specific MCP-1 deletion in these models, there is a possibility that effects may be observed in other models of disease. This 
may be especially true in chronic models of inflammation, in cases of monocyte-macrophage infection with intracellular pathogens, such as L. monocytogenes or in tumor-associated macrophages in cancer. Therefore, our MCP-1 $1^{\text {flox/flox }}$ mice will be a great tool to investigate the relative contribution of different cell types to the development of immune responses and also cancer in which MCP-1 contribute to its progression.

\section{AUTHOR CONTRIBUTIONS}

Teizo Yoshimura performed the majority of experiments, and wrote the paper; Carole Galligan, Munehisa Takahashi, and Lino Tessarollo contributed to the generation of MCP-1 floxed mice; Keqiang Chen helped in experimental design; Mingyong Liu performed ELISA; Ji Ming Wang helped in experimental design and reviewed the paper.

\section{ACKNOWLEDGMENTS}

We are grateful to Steven Stull, Timothy Back, and staff of LASP, SAIC-Frederick, Inc., for their assistance in animal studies. We are also grateful to Dr. Joost J. Oppenheim for his critical comments. This research was supported by the Intramural Research Program of the NIH, NCI, and National Cancer Institute, National Institutes of Health Contract HHSN261200800001E.

\section{REFERENCES}

1. Rossi D, Zlotnik A. The biology of chemokines and their receptors. Ann Rev Immunol (2000) 18:217-42. doi:10.1146/annurev.immunol.18.1.217

2. Ma Q, Jones D, Springer TA. The chemokine receptor CXCR4 is required for the retention of $\mathrm{b}$ lineage and granulocytic precursors within the bone marrow microenvironment. Immunity (1999) 10:463-71. doi:10.1016/S1074-7613(00) 80046-1

3. Nagasawa T, Hirota S, Tachibana K, Takakura N, Nishikawa S, Kitamura $\mathrm{Y}$, et al. Defects of B-cell lymphopoiesis and bone-marrow myelopoiesis in mice lacking the CXC chemokine PBSF/SDF-1. Nature (1996) 382:635-8. doi:10.1038/382635a0

4. Szekanecz Z, Koch AE. Chemokines and angiogenesis. Curr Opin Rheumatol (2001) 13:202-8. doi:10.1097/00002281-200105000-00009

5. Tran PB, Miller RJ. Chemokine receptors: signposts to brain development and disease. Nat Rev Neurosci (2003) 4:444-55. doi:10.1038/nrn1116

6. Berger EA, Murphy PM, Farber JM. Chemokine receptors as HIV-1 coreceptors: roles in viral entry, tropism, and disease. Ann Rev Immunol (1999) 17:657-700. doi:10.1146/annurev.immunol.17.1.657

7. Mantovani A, Allavena P, Sica A, Balkwill F. Cancer-related inflammation. Nature (2008) 454:436-44. doi:10.1038/nature07205

8. Proudfoot AE. Chemokine receptors: multifaceted therapeutic targets. Nat Rev Immunol (2002) 2:106-15. doi:10.1038/nri722

9. Murphy PM, Baggiolini M, Charo IF, Hebert CA, Horuk R, Matsushima K, et al. International union of pharmacology. Xxii. Nomenclature for chemokine receptors. Pharmacol Rev (2000) 52:145-76.

10. Sozzani S. Dendritic cell trafficking: more than just chemokines. Cytokine Growth Factor Rev (2005) 16:581-92. doi:10.1016/j.cytogfr.2005.04.008

11. Yoshimura T, Ueda A. Monocyte chemoattractant protein-1. In: Aggarwal BB, Gutterman JU, editors. Human Cytokines: Handbook for Basic and Clinical Research, II. Cambridge, MA: Blackwell Science (1996). p. 198-221.

12. Yadav A, Saini V, Arora S. Mcp-1: chemoattractant with a role beyond immunity: a review. Clin Chim Acta (2010) 411:1570-9. doi:10.1016/j.cca.2010.07.006

13. Hildebrand DG, Alexander E, Hörber S, Lehle S, Obermayer K, Münck NA, et al. Iкb $\zeta$ is a transcriptional key regulator of ccl2/mcp-1. J Immunol (2013) 190:4812-20. doi:10.4049/jimmunol.1300089

14. Takahashi M, Galligan C, Tessarollo L, Yoshimura T. Monocyte chemoattractant protein-1 (MCP-1), not MCP-3, is the primary chemokine required for monocyte recruitment in mouse peritonitis induced with thioglycollate or zymosan a. J Immunol (2009) 183:3463-71. doi:10.4049/jimmunol.0802812
15. Clausen BE, Burkhardt C, Reith W, Renkawitz R, Forster I. Conditional gene targeting in macrophage and granulocytes using lysmcre mice. Transgenic Res (1999) 8:265-77. doi:10.1023/A:1008942828960

16. Zhang N, Yang D, Dong H, Chen Q, Dimitrova DI, Rogers TJ, et al. Adenosine A2a receptors induce heterologous desensitization of chemokine receptors. Blood (2006) 108:38-44. doi:10.1182/blood-2005-06-2599

17. Yoshimura T, Johnson DG. The cDNA cloning and expression of guinea pig neutrophil attractant protein-1 (NAP-1): NAP-1 is highly conserved in guinea pig. J Immunol (1993) 151:6225-36.

18. Sylvester I, Suffredini AF, Boujoukos AJ, Martich GD, Danner RL, Yoshimura T, et al. Neutrophil attractant protein-1 (NAP-1) and monocyte chemoattractant protein-1 (MCP-1) in human serum: effects of intravenous LPS on free attractants, specific IgG autoantibodies and immune complexes. J Immunol (1993) 151:3292-8.

19. Yoshimura T, Howard OMZ, Ito T, Kuwabara M, Matsukawa A, Chen K, et al. Monocyte chemoattractant protein-1/CCL2 produced by stromal cells promotes lung metastasis of 4T1 murine breast cancer cells. PLoS One (2013) 8:e58791. doi:10.1371/journal.pone.0058791

20. Koch AE, Kunkel SL, Harlow LA, Johnson B, Evanoff HL, Haines GK, et al. Enhanced production of monocyte chemoattractant protein-1 in rheumatoid arthritis. J Clin Invest (1992) 90:772-9. doi:10.1172/JCI115950

21. Matsukawa A, Miyazaki S, Maeda T, Tanase S, Feng L, Ohkawara S, et al. Production and regulation of MCP-1 in lipopolysaccharide or monosodium urate crystal-induced arthritis in rabbits: roles of TNF, IL-1, and IL-8. Lab Invest (1998) 78:973-85.

22. Sedgwick AD, Sin YM, Edwards JC, Willoughby DA. Increased inflammatory reactivity in newly formed lining tissue. J Pathol (1983) 14:483-95. doi:10.1002/path.1711410406

23. Murray PJ, Wynn TA. Protective and pathogenic functions of macrophage subsets. Nat Rev Immunol (2011) 11:723-37. doi:10.1038/nri3073

24. Takeya M, Yoshimura Y, Leonard EJ, Takahashi K. Detection of monocyte chemoattractant protein-1 (MCP-1) in human atherosclerotic lesions by an anti-monocyte chemoattractant protein-1 monoclonal antibody. Hum Pathol (1993) 24:534-9. doi:10.1016/0046-8177(93)90166-E

25. Ajuebor MN, Das AM, Virág L, Flower RJ, Szabó C, Perretti M. Role of resident peritoneal macrophages and mast cells in chemokine production and neutrophil migration in acute inflammation: evidence for an inhibitory loop involving endogenous IL-10. J Immunol (1999) 162:1685-91.

26. Mutsaers SE. The mesothelial cell. Int J Biochem Cell Biol (2004) 36:9-16. doi:10.1016/S1357-2725(03)00242-5

27. Park JH, Kim YG, Shaw M, Kanneganti TD, Fujimoto Y, Fukase K, et al. Nod1/rick and tlr signaling regulate chemokine and antimicrobial innate immune responses in mesothelial cells. J Immunol (2007) 179:514-21.

28. Chao J, Wood JG, Gonzalez NC. Alveolar macrophages initiate the systemic microvascular inflammatory response to alveolar hypoxia. Respir Physiol Neurobiol (2011) 178:439-48. doi:10.1016/j.resp.2011.03.008

29. Standiford TJ, Kunkel SL, Phan SH, Rollins BJ, Strieter RM. Alveolar macrophage-derived cytokines induce monocyte chemoattractant protein-1 expression from human pulmonary type II-like epithelial cells. J Biol Chem (1991) 266:9912-8.

Conflict of Interest Statement: The authors declare that the research was conducted in the absence of any commercial or financial relationships that could be construed as a potential conflict of interest.

Received: 06 November 2013; paper pending published: 27 November 2013; accepted: 09 December 2013; published online: 07 January 2014.

Citation: Yoshimura T, Galligan C, Takahashi M, Chen K, Liu M, Tessarollo L and Wang JM (2014) Non-myeloid cells are major contributors to innate immune responses via production of monocyte chemoattractant protein-1/CCL2. Front. Immunol. 4:482. doi: 10.3389/fimmu.2013.00482

This article was submitted to Chemoattractants, a section of the journal Frontiers in Immunology.

Copyright (C) 2014 Yoshimura, Galligan, Takahashi, Chen, Liu, Tessarollo and Wang. This is an open-access article distributed under the terms of the Creative Commons Attribution License (CC BY). The use, distribution or reproduction in other forums is permitted, provided the original author(s) or licensor are credited and that the original publication in this journal is cited, in accordance with accepted academic practice. No use, distribution or reproduction is permitted which does not comply with these terms. 